\title{
Intra-cardiac MR imaging \& MR-tracking catheter for improved MR-guided EP
}

\author{
Yue Chen ${ }^{1 *}$, Zion T Tse', Wei Wang ${ }^{2}$, Raymond Y Kwong ${ }^{3}$, William G Stevenson ${ }^{3}$, Ehud J Schmidt ${ }^{2}$ \\ From 18th Annual SCMR Scientific Sessions \\ Nice, France. 4-7 February 2015
}

\begin{abstract}
Background
Electrophysiology (EP) studies can diagnose \& treat patients with arrhythmia. MR-guided EP is growing, driven by the ability of cardiac MRI to provide high-contrast images. For intra-procedural use, MRI provides images of the acute state of radio-frequency ablation (RFA) lesions, e.g. necrosis, edema and hemorrhage, that potentially reduce recurrences \& complications [1,2]. Unfortunately, acquisition of these images using surface MRI coils, considering the high-spatial-resolution $\left(\sim 1 \times 1 \times 2 \mathrm{~mm}^{3}\right)$ requirements, can be lengthy (scar $10 \mathrm{mins} / \mathrm{scan}$, edema 12 mins/scan) [3], severely increasing the duration of MR-guided procedures. As demonstrated in other body regions, e.g. endorectal MRI, and with other imaging modalities (Intra-Cardiac Echo), intracavitary probes provide increased Signal-to-Noise-Ratio (SNR), due to their proximity to the area of interest. An Intra-cardiac MR imaging (ICMRI) coil may provide substantially higher SNR, but a complete application must also provide accurate heart motion compensation [4], in order to produce non-blurred images. We constructed an ICMRI catheter, with integrated imaging \& positional-tracking elements, optimized for (1) cardiovascular introduction as a sheath "riding on" an EP ablation catheter \& for (2) close-proximity imaging ( $\sim 4 \mathrm{~cm}$ FOV) during RFA delivery.
\end{abstract}

\section{Methods}

The ICMRI catheter consists of a deployable imaging coil $\& 4$ tracking micro-coils at the catheter tip. The imaging coil is folded during vascular navigation $(4.5-\mathrm{mm}$ diameter). During the expansion, the imaging coil forms a circular loop of $40 \mathrm{~mm}$ in diameter which images a $\sim 4 \mathrm{~cm}$
FOV, while the tracking coils form a tetrahedral array (Fig. 1a-b, d-f) for accurate motion-compensation [4]. The imaging coil, constructed of two windings of 38-gauge copper wire, was woven into an expandable protective nylon mesh. The foldable plastic arms (Fig. 1d), covered by the nylon mesh, provide a tetrahedral structure on which the 4 tracking micro-coils $(2 \mathrm{~mm}$ diameter) were mounted. The imaging coil was connected to a $123 \mathrm{MHz}$ (3T) miniaturized tuning/matching circuit in a pocket on the ICMRI sheath (Fig. 1c) $(\sim 11 \mathrm{~dB}$ reflection-coefficient, loaded). To evaluate imaging performance, the ICMRI was compared to a 32-channel Invivo cardiac-array during ex-vivo swine left-ventricular (LV) \& left-atrial (LA) imaging.

\section{Results}

ICMRI provided 2-4 times the SNR of the Invivo array at distances of $5-8 \mathrm{~cm}$ from the coil, for both T1-W GRE and T2-w TSE (Fig. 2). Efficient breath-hold $(20-\mathrm{sec}) \mathrm{T} 2-\mathrm{w}$ scans were also possible. Operation in tandem with an MR-compatible EP ablation catheter (St. Jude Medical) was also demonstrated.

\section{Conclusions}

The ICMRI catheter allows for 4-16x faster imaging during MR-guided RFA, improving temporal efficiency. ICMRI supports catheterization, in analogy with ICE's advantages (trans-septal puncture, valve passage), supporting low-SNR imaging contrasts (Strain, Diffusion).

\section{Funding}

AHA 10SDG261039, NIH R03 EB013873-01A1, NIH U41-RR019703.

${ }^{1}$ Engineering, The University of Georgia, Athens, GA, USA

Full list of author information is available at the end of the article 
a)

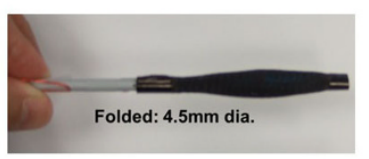

d) Foldable plastic arm closed

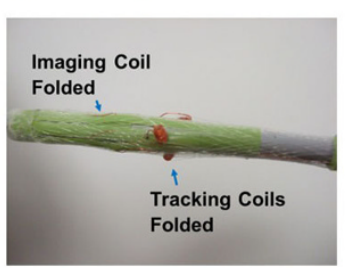

b)

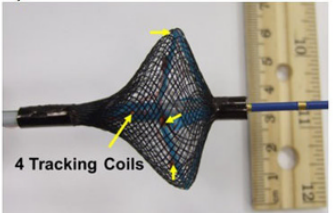

e) Tracking coils supported on tetrahedral structure

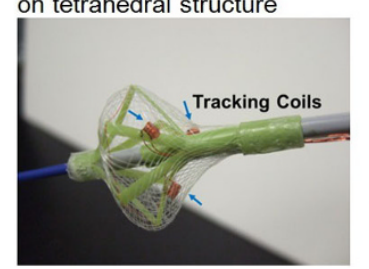

c)

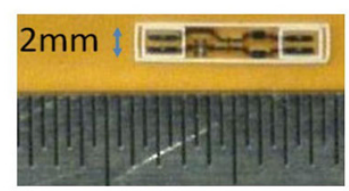

f) The imaging coil expanded

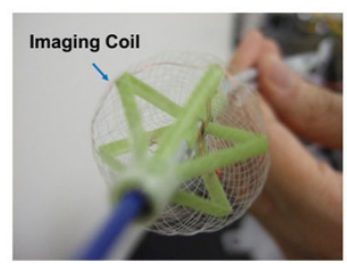

Figure 1 ICMRI catheter with imaging coil (a) collapsed to allow navigation within the vasculature, and (b) expanded for imaging; (c) tuning/ matching micro-electronics. ICMRI without protective nylon mesh, showing the foldable plastic arm structure, on which both the imaging and tracking coils were mounted, during closing (d) and opening (e-f).
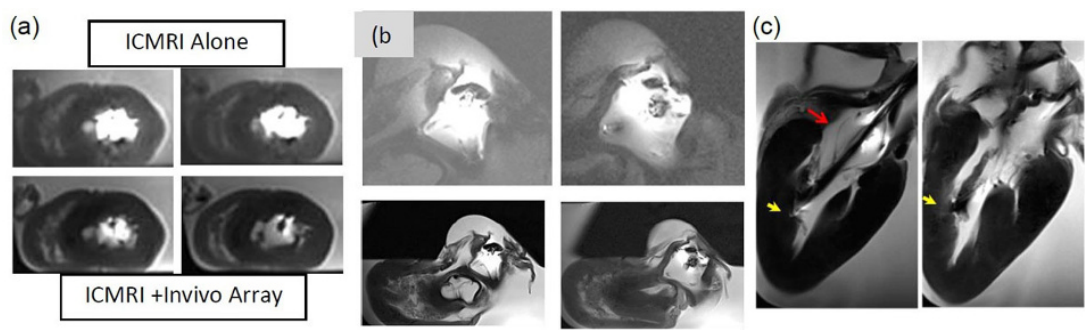

Figure 2 ICMRI imaging at 3T (a) Breath-held T2-w; LV short-axis; ICMRI alone (Top) versus ICMRI+ Invivo array (Bottom), (b) LA short axis; ICMRI alone (Top, 2.1X magnified) versus ICMRI+Invivo array (Bottom, 1X magnified); (c) LV long-axis T2-W. ICMRI catheter (red arrow) mounted on EP ablation catheter, showing the EP catheter tip (yellow arrows) contacting the papillary muscle.

\section{Authors' details}

'Engineering, The University of Georgia, Athens, GA, USA. ${ }^{2}$ Radiology,

Brigham and Women's Hospital, Boston, MA, USA. ${ }^{3}$ Cardiology, Brigham and

Women's Hospital, Boston, MA, USA.

Published: 3 February 2015

\section{References}

1. Schmidt: MRM14.

2. Reddy: I Cardiovascular EP08

3. Schmidt: Circ: Arrhythmia \& EPO9.

4. Qin: MRM13

doi:10.1186/1532-429X-17-S1-P237

Cite this article as: Chen et al: Intra-cardiac MR imaging \& MR-tracking catheter for improved MR-guided EP. Journal of Cardiovascular Magnetic Resonance 2015 17(Suppl 1):P237.

\section{Submit your next manuscript to BioMed Central and take full advantage of:}

- Convenient online submission

- Thorough peer review

- No space constraints or color figure charges

- Immediate publication on acceptance

- Inclusion in PubMed, CAS, Scopus and Google Scholar

- Research which is freely available for redistribution

Submit your manuscript at www.biomedcentral.com/submit
C Biomed Central 